\title{
PENGABDIAN KEPADA MASYARAKAT BERBASIS PONDOK PESANTREN OLEH MAHASISWA KKN STIBA MAKASSAR DI KABUPATEN JENEPONTO
}

\section{BOARDING-SCHOOL-BASED COMMUNITY SERVICE BY STUDENTS OF KKN STIBA MAKASSAR IN JENEPONTO REGENCY}

\author{
Ihwan Wahid Minu \\ Sekolah Tinggi Ilmu Islam dan Bahasa Arab (STIBA) Makassar \\ ihwanwahid@stiba.ac.id \\ Kasman Bakry \\ Sekolah Tinggi Ilmu Islam dan Bahasa Arab (STIBA) Makassar \\ kasmanbakry@stiba.ac.id \\ Abdullah Nazhim Hamid \\ Sekolah Tinggi Ilmu Islam dan Bahasa Arab (STIBA) Makassar \\ abufauzangeologi@gmail.com
}

\begin{tabular}{|c|c|}
\hline Keywords: & ABSTRACT \\
\hline $\begin{array}{l}\text { Boarding School, Jeneponto } \\
\text { Regency, Qur'anic Education. }\end{array}$ & $\begin{array}{l}\text { Pondok Pesantren (Boarding Schools) is one of the educational } \\
\text { services that are quite influential in the development of Muslim } \\
\text { communities in Indonesia, including in the Region of South } \\
\text { Sulawesi. One of the Boarding Schools located in Jeneponto } \\
\text { Regency, South Sulawesi, is Pondok Pesantren Ulul Albab. Pondok } \\
\text { Pesantren Ulul Albab focuses on the construction of memorization } \\
\text { and teaching of the Qur'an. In addition, this boarding schools also } \\
\text { continues to carry out formal learning in the classroom. therefore, } \\
\text { Pondok Pesantren Ulul Albab became one of the destinations } 4^{\text {th }} \\
\text { KKN STIBA Makassar IV. The purpose of this Field Work Lecture } \\
\text { (KKN) STIBA Makassar is to realize community service which is a } \\
\text { pillar of the tri dharma of higher education in Indonesia. The } \\
\text { method of community service implementation in Pondok Pesantren } \\
\text { Ulul Albab begins with mapping the problems and needs of } \\
\text { boarding schools by using instruments made simply by SOAR } \\
\text { analysis. After that, mapping the work program that suits the needs } \\
\text { of boarding schools. The program of activities carried out by } \\
\text { students of STIBA Makassar is Qur'an and tahsin education, } \\
\text { classroom learning, Friday sermons, lecture training, and } \\
\text { devotional work. The results of the KKN program can be seen from } \\
\text { enthusiastic students and teachers who are getting better at } \\
\text { learning and teaching the Qur'an. It also provides a new learning } \\
\text { experience for teachers and students. }\end{array}$ \\
\hline \multirow{2}{*}{$\begin{array}{l}\text { Kata kunci : } \\
\text { Pondok Pesantren, Kabupaten } \\
\text { Jeneponto, Pendidikan Al- } \\
\text { Qur'an, }\end{array}$} & ABSTRAK \\
\hline & $\begin{array}{l}\text { Pondok Pesantren (ponpes) merupakan Lembaga pendidikan yang } \\
\text { cukup mewarnai perkembangan masyarakat muslim di Indonesia, } \\
\text { tidak terkecuali di Wilayah Sulawesi Selatan. Salah satu Pondok }\end{array}$ \\
\hline
\end{tabular}




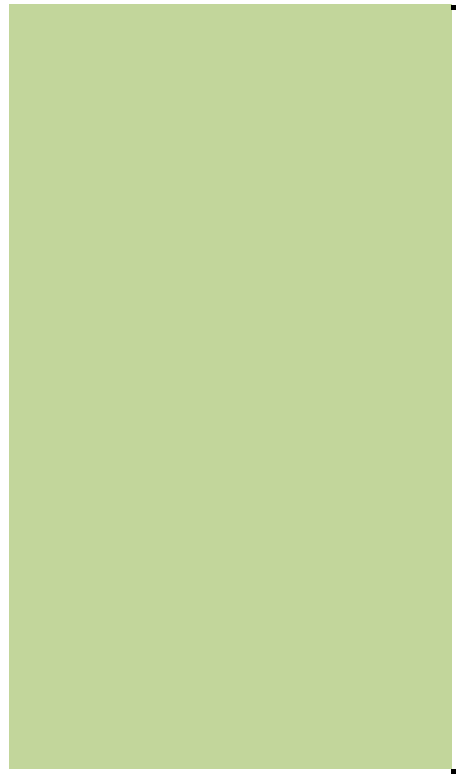

\begin{abstract}
Pesantren yang terletak di Kabupaten Jeneponto, Sulawesi Selatan, adalah Pondok Pesantren Ulul Albab. Ponpes Ulul Albab berfokus pada pembinaan hafalan dan pengajaran Al-Qur'an. Selain itu, ponpes ini juga tetap melaksanakan pembelajaran formal dalam kelas. Tujuan dari Kuliah Kerja Nyata (KKN) STIBA Makassar angkatan IV ini adalah sebagai wujud pengabdian kepada masyarakat yang merupakan pilar dari tri dharma perguruan tinggi di Indonesia. Metode pelaksanaan pengabdian kepada masyarakat di Ponpes Ulul Albab ini diawali dengan memetakan masalah dan kebutuhan ponpes dengan menggunakan instrument yang dibuat secara sederhana yaitu dengan analisis SOAR. Setelah analisis dilakukan, maka dipetakan program kerja yang sesuai dengan kebutuhan ponpes. Program kerja yang dicanangkan oleh mahasiswa STIBA Makassar adalah pendidikan Al-Qur'an dan tahsin, pembelajaran dalam kelas, khotbah Jumat, pelatihan ceramah, dan kerja bakti. Hasil dari program KKN terlihat dari antusias santri dan guru yang semakin baik dalam belajar dan mengajarkan Al-Qur'an. Hal tersebut juga memberikan pengalaman belajar yang baru bagi para guru dan santri.
\end{abstract}

Diterima: 18 April 2021; Direvisi: 10 Mei 2021; Disetujui: 28 Mei 2021; Tersedia online: 18 Juni 2021

How to cite: Ihwan Wahid Minu, Kasman Bakry, Abdullah Nazhim Hamid "Pengabdian kepada Masyarakat Berbasis Pondok Pesantren oleh Mahasiswa KKN STIBA Makassar di Kabupaten Jeneponto", WAHATUL MUJTAMA': Jurnal Pengabdian Masyarakat Vol.2, No.1 (Juni 18, 2021): 49-57. doi: https://doi.org/10.36701/wahatul.v2i1.344

\title{
PENDAHULUAN
}

Letak Geografi Kabupaten Jeneponto terletak antara 5o23'12" - 5o42'1,2” Lintang Selatan dan 119o29'12" - 119o56'44,9" Bujur Timur, dengan jumlah penduduk mencapai 342.700 jiwa pada tahun 2010. Berbatasan dengan Kabupaten Gowa dan Takalar di sebelah Utara, Kabupaten Bantaeng di sebelah Timur, Kabupaten Takalar sebelah Barat dan Laut Flores di sebelah Selatan. Luas wilayah Kabupaten Jeneponto tercatat 749,79 km persegi yang meliputi 114 desa dan kelurahan, 11 kecamatan, yaitu: Kecamatan Bangkala, Batang, Kelara, Binamu, Tamalatea, Bontoramba, Rumbia, Turatea, Tarowang, Arungkeke, Bangkala Barat. Kabupaten Jeneponto terletak di ujung bagian Barat wilayah Propinsi Sulsel yang jarak tempuhnya dari Kota Makassar sekitar $90 \mathrm{~km}$. Topografi Kabupaten Jeneponto pada bagian Utara terdiri dari dataran tinggi dengan ketinggian 500 sampai dengan 1400 meter di atas permukaan laut, bagian tengah dengan ketinggian 100 sampai dengan 500 meter dari permukaan laut, dan pada bagian Selatan meliputi wilayah dataran rendah dengan ketinggian 0 sampai dengan 150 meter di atas permukaan laut. Bagian barat dan utara pada umumnya merupakan pegunungan, dan bagian selatan sebagian besar merupakan dataran rendah. Tingkat kemiringan rata-rata pada wilayah bagian barat dan utara $40^{\circ}$, 
dengan rata-rata curah hujan lebih tinggi bila dibanding dengan bagian wilayah lainnya ${ }^{1}$.

Kabupaten Jeneponto juga dikenal sebagi penghasil nener dan benur ikan bandeng yang banyak dibudidayakan di Sulawesi Selatan. Wilayah Pesisir Kabupaten Jeneponto yang merupakan sentra produksi garam satu-satunya di pulau Sulawesi. Produksi garam tidak hanya mencukupi kebutuhan garam yodium untuk provinsi Sulawesi Selatan saja, tetapi juga menyuplai kebutuhan di kawasan timur Indonesia. Kabupaten Jeneponto juga memiliki potensi pohon lontar (siwalan) yang begitu besar jumlahnya yang tersebar pada semua kecamatan, sangat memungkinkan untuk pengembangan sentra industri gula merah. Saat ini pengelolaan gula merah rakyat masih dikelola secara tradisional sehingga diperlukan adanya terknologi yang lebih modern untuk pengolahan gula merah yang diharapkan dapat menghasilkan produk gula merah dengan kualitas yang bersaing.

Berdasarkan profil singkat daerah $\mathrm{KKN}$ di atas, maka pelaksanaan program KKN STIBA Makassar angkatan IV diharapkan dapat memberikan kontribusi yang besar dalam peningkatan SDM masyarakat, dalam hal ini secara khusus para santri di Pondok Pesantren Ulul Albab Jeneponto. Untuk itu, ditetapkan beberapa tujuan pelaksanaan KKN sebagai berikut:

1. Untuk mengambil peran dalam membantu pihak pesantren dalam pengelolaan dan pembinaan santri.

2. Untuk meningkatkan kesadaran sosial dakwah bagi mahasiswa STIBA Makassar dalam berkontribusi pada peningkatan manajemen pembinaan santri di pesantren.

3. STIBA Makassar sebagai perguruan tinggi agama Islam yang berkewajiban dalam melaksanakan Tri Darma Perguruan Tinggi pada pilar pengabdian masyarakat.

Sebelum itu, dalam pelaksanaan program KKN maka terlebih dahulu dilakukan survey lapangan untuk keperluan analisis kebutuhan program pemberdayaan masyarakat. Dengan mengaplikasikan instrumen sederhana dalam memetakan masalah dan kebutuhan, maka dilakukan analisis SOAR sebagai berikut:

1. Strength, Pondok Pesantren Ulul Albab memiliki lingkungan Islami yang medukung para santri dalam melakukan ibadah dan aktivitas Islami lainnya.

2. Opportunities, dukungan penuh dari pihak pengelola dan pembina Pondok Pesantren Ulul Albab. Termasuk juga penerimaan dan antusias yang besar dari semua santri dengan adanya program KKN ini.

\footnotetext{
${ }^{1}$ Profil Kabupaten Jeneponto
} 
3. Aspiration, Pondok Pesantren Ulul Albab masih membutuhkan manajemen yang baik dalam pembinaan. Baik dalam pembentukan karakter santri maupun dalam manajemen pembelajar yang efisien. Selain itu, beberapa fasilitas tampak kurang sehingga sedikit menghambat proses pembinaan santri.

4. Result, Pondok Pesantren Ulul Albab mampu melahirkan santriwan maupun santriwati dengan karakter dan akhlak Islami yang berkualitas, mampu menghafal Al-Qur'an dengan baik serta memiliki kapasitas ilmu syar'i yang mumpuni.

Berdasarkan hasil analisis SOAR di atas, maka ditetapkanlah program kerja KKN STIBA Makassar angkatan IV di Pondok Pesantren Ulul Albab yaitu, pembelajaran Al-Qur'an dan tahsin, khotbah Jumat, pelatihan ceramah, dan kerja bakti. Program kerja ini, diharapkan dapat memberikan sedikit kontribusi dalam pembinaan santri di Pondok Pesantren Ulul Albab.

Sehubungan dengannya, hasil-hasil pengabdian masyarakat telah banyak dilakukan oleh pelaksana PkM dan dijumpai banyak artikel berkenaan dengannya. Berikut beberapa artikel hasil $\mathrm{PkM}$ terdahulu dan relevan dengan PkM ini ditampilkan sebagai berikut:

1. PkM yang dilakukan oleh Nurul Azizah dkk. mengenai pendidikan perilaku hidup bersih dan sehat (PHBS) yang belum pernah didapatkan oleh santri Pondok Pesantren Al-Hamdaniyah Buduran, Sidoarjo. Di pondok ini juga tampak tidak ada poskestren dan kader kesehatan sehingga yang sakit kadang tidak terurus. Dalam kegiatan ini, dilakukan ceramah tentang perilaku hidup bersih dan sehat di lingkungan pondok pesantren, pembentukan dan bimbingan kader kesehatan, serta pengadaan poskestren di lingkungan pondok pesantren. Hasil yang dicapai dalam kegiatan ini adalah peningkatan pengetahuan tentang perilaku hidup bersih dan sehat di lingkungan pondok pesantren, dan terbentuknya kader kesehatan yang mampu menjalankan pelayanan kesehatan di lingkungan pondok pesantren. Selain itu, diupayakan tersedianya poskestren baru yang dapat menjadi fasilitas tambahan dan bermanfaat bagi santri².

2. Penelitian yang dilakukan oleh Rustam Ibrahim menyoal tentang peran pesantren dalam pengabdian kepada masyarakat. Dalam penelitian ini, ditemukan bahwa beberapa pesantren belum dapat menerima dan berperan dalam pengabdian kepada masyarakat. Survey BPPM Pesantren Maslakul Huda bekerja sama dengan PM Jakarta menyimpulkan bahwa 3 (25\%) dari 12

${ }^{2}$ Nurul Azizah et al., "Phbs Santri Dan Aplikasi Poskestren Pondok Pesantren AlHamdaniyah Buduran Siwalan Panji Sidaorjo," Jurnal Pengabdian Masyarakat Dalam Kesehatan 2, no. 1 (2020): 22, https://doi.org/10.20473/jpmk.v2i1.19583. 
pesantren se-Jawa Tengah tidak menerima pengabdian masyarakat. Padahal pesantren merupakan pendidikan yang lahir dan besar dari masyarakat. Penelitian ini menemukan bahwa pengabdian PP Dawar, baik dalam keagamaan maupun pemberdayaan ekonomi, serta alasan utama PP Dawar melakukan pengabdian pada masyarakat. Berdasarkan penelitian, ditemukan bukti bahwa PP Dawar adalah pesantren berbasis masyarakat, yaitu dengan melaksanakan pengabdian keagamaan, seperti pengajian rutin, pengajian yatiman, juga melayani permintaan masyarakat yang membutuhkan ustaz atau guru agama lulusan PP Dawar Boyolali. PP Dawar juga ikut membantu ekonomi masyarakat sekitar, yaitu menyediakan tenaga murah, membantu home industry pembuatan sapu, kerupuk, dan menyelenggarakan santunan 500 anak yatim. Pemikiran yang mendasari pengabdian PP Dawar adalah rasa keikhlasan, mengamalkan ilmu agama, semangat kemandirian, dan promosi bagi PP Dawar Boyolali ${ }^{3}$.

\section{PEMBAHASAN}

\section{Pendidikan Al-Qur'an dan Tahsin}

Tujuan utama dari program ini adalah agar dapat membantu para santri membaca Al-Qur'an dengan baik, sehingga mendukung prosesnya dalam menghafal Al-Qur'an. Sehubungan dengannya pula, Asnawati dan Rahmat menyatakan bahwa kegiatan Tahsin Al-Qur'an bertujuan untuk mengenalkan makhraj huruf hijaiah sehingga mampu membedakan penyebutan setiap huruf dan mampu membaca Al-Qur'an dengan baik dan benar sesuai ilmu tajwid ${ }^{4}$. Dengan demikian, bacaan dan hafalan Al-Qur'an para santri semakin baik.

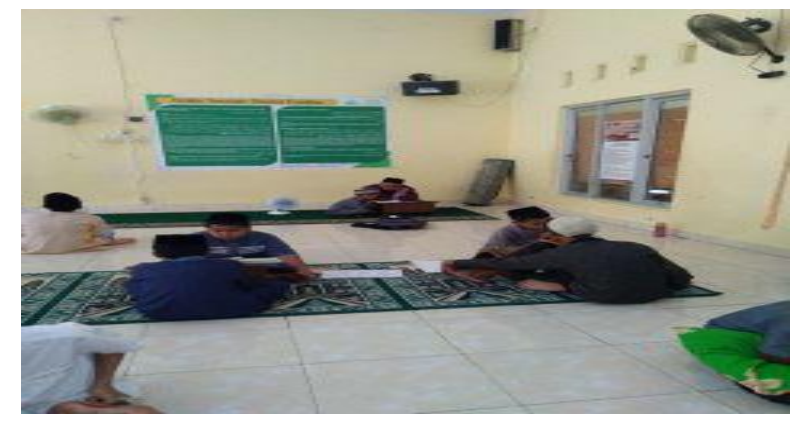

Gambar 1. Pendidikan Al-Qur'an dan Tahsin

\footnotetext{
${ }^{3}$ Rustam Ibrahim, "Pesantren Dan Pengabdian Masyarakat (Studi Kasus Pondok Pesantren Dawar Boyolali)," Al-Tahrir: Jurnal Pemikiran Islam 16, no. 1 (2016): 89, https://doi.org/10.21154/al-tahrir.v16i1.316.

${ }^{4}$ Patuti, Asnawati. "Pelaksanaan Program Pendekatan Keagamaan melalui KKN STIBA Makassar di Desa Baruga Kabupaten Maros." WAHATUL MUJTAMA': Jurnal Pengabdian Masyarakat 1.2 (2020): 185-199.
} 
Program ini diadakan tiga kali dalam sehari, yaitu setelah subuh, setelah Asar, dan setelah Isya. Sasaran dari program ini adalah seluruh santriwan yang berada di pondok. Kegiatan ini dilaksanakan di Masjid Ahlul Qur'an. Namun, terbatasanya sarana dan prasarana dalam pondok, membuat sebagian santri tidak maksimal dalam belajar dan menghafal Al-Qur'an.

\section{Pengajaran dalam Kelas}

Tujuan dari program ini yaitu untuk meningkatkan kemampuan mahasiswa KKN dalam menyampaikan ilmu melalui sekolah formal. Selain itu, tujuan mendasar dari pengajaran dalam kelas adalah mengajarkan agama Islam kepada para peserta didik ${ }^{5}$. Waktu mengajar mahasiswa KKN disesuaikan dengan waktu guru Ponpes yang ingin digantikan. Sasaran dari program ini adalah seluruh santriwan SMP IT Pondok Pesantren Ulul Albab Jenenponto. Proses pengajaran ini dilaksanakan di gedung sekolah SMP IT. Namun, yang menjadi kendala adalah jauhnya jarak gedung sekolah dengan tempat menghafal, sehingga mengharuskan seluruh santriwan berjalan kaki dengan jarak kurang lebih 800 meter. Untuk itu, mahasiswa KKN perlu memberikan motivasi kepada para santri agar selalu bersemangat dalam menuntut ilmu keislaman.

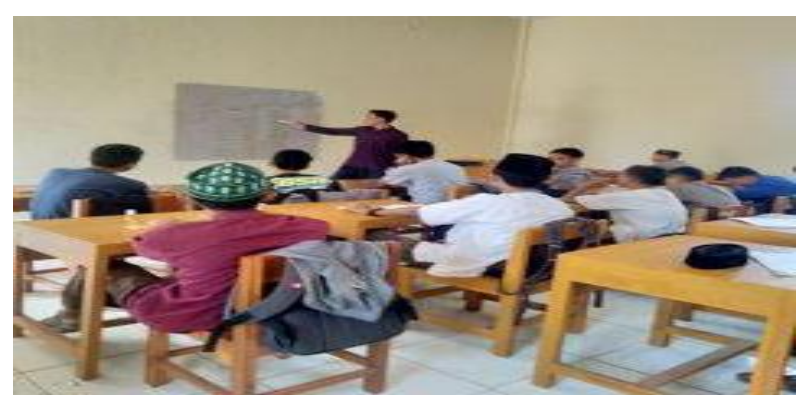

Gambar 2. Proses Pengajaran dalam Kelas

\section{Khotbah Jumat}

Tujuan program ini adalah untuk meningkatkan skills mahasiswa KKN dalam berbicara di depan umum. Selain itu, manfaat dari program Khotbah Jumat adalah membantu pemerintah setempat dalam menyemarakkan pelaksanaan ibadah Jumat yang sering terkendala dengan kurangnya dai dan khatib setiap Jumat $^{6}$.

5 Ariesman, Ariesman. "Sketsa Dakwah dan Pembinaan Qur'ani Masyarakat Desa Mangeloreng Melalui KKN STIBA Makassar." WAHATUL MUJTAMA': Jurnal Pengabdian Masyarakat 1.1 (2020): 13-32.

6 Tempo, Rachmat Bin Badani, and Khaerul Aqbar. "Ikhtiar Mahasiswa KKN STIBA Makassar dalam Pembentukan Akhlak Qur'ani Masyarakat Desa Balassuka Kabupaten Gowa." WAHATUL MUJTAMA': Jurnal Pengabdian Masyarakat 1.1 (2020): 90-115. 


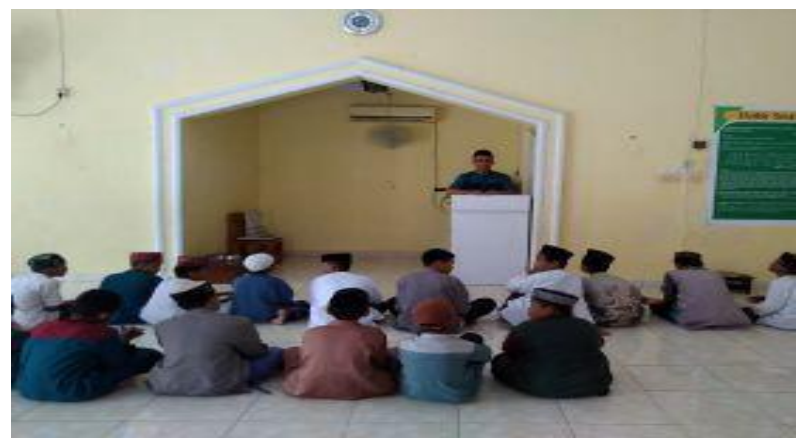

Gambar 3. Khotbah Jumat di Masjid

Program ini juga membantu DPD Wahdah Islamiyah Jenenponto dalam menyiapkan khatib setiap hari Jumat di beberapa masjid. Dari program ini, mahasiswa KKN dipercayakan memberikan khotbah Jumat di Masjid Al-Huda, Masjid Alhul Qur'an, dan Masjid Al-Husain. Sasaran dari program ini adalah masyarakat dan para santriwan. Salah satu kendala yang dihadapi mahasiswa dalam program ini karena tidak ada moda transportasi sehingga mahasiswa hanya bias meminjam kendaraan dari salah satu ustdaz yang berada disana.

\section{Pelatihan Ceramah}

Tujuan dari kegiatan ini adalah untuk meningkatkan kemampuan para santri dalam berbicara di depan umum, dan juga berimplikasi pada peningkatan kepercayaan diri santri.

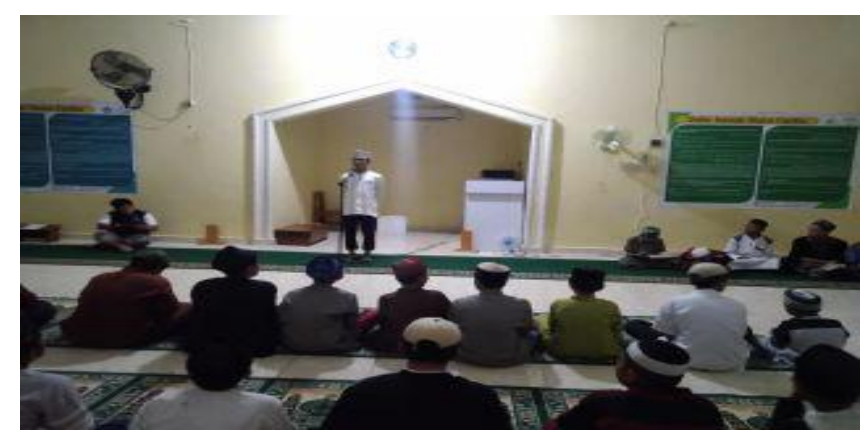

\section{Gambar 4. Latihan Ceramah Para Santriwan}

Program ini juga menjadi bahan latihan bagi mereka untuk persiapan ceramah di bulan Ramadan. Program ini dilaksankan di Pondok Pesantren Ulul Albab. Sasarannya adalah seluruh santriwan ponpes Ulul Albab. Kegiatan ini dilaksanakan setiap malam senin. Dalam program ini, tidak ada hambatan maupun kendala yang berarti. 


\section{Kerja Bakti dan Buka Puasa Bersama}

Tujuan kegiatan ini adalah untuk menumbuhkan rasa peduli terhadap lingkungan, sekaligus mempererat rasa solidaritas antar santri. Untuk itu, diperlukan usaha kerja sama dalam membersihkan lingkungan pesantren, serta membutuhkan tim yang solid. Lokasi kegiatan ini adalah di lingkungan Pondok Pesantren Ulul Albab Jeneponto. Sasarannya adalah seluruh santriwan yang berada di lingkungan ponpes. Kegiatan ini dilaksankan setiap Sabtu setelah Asar. Tidak ada kendala yang berarti dalam program ini.

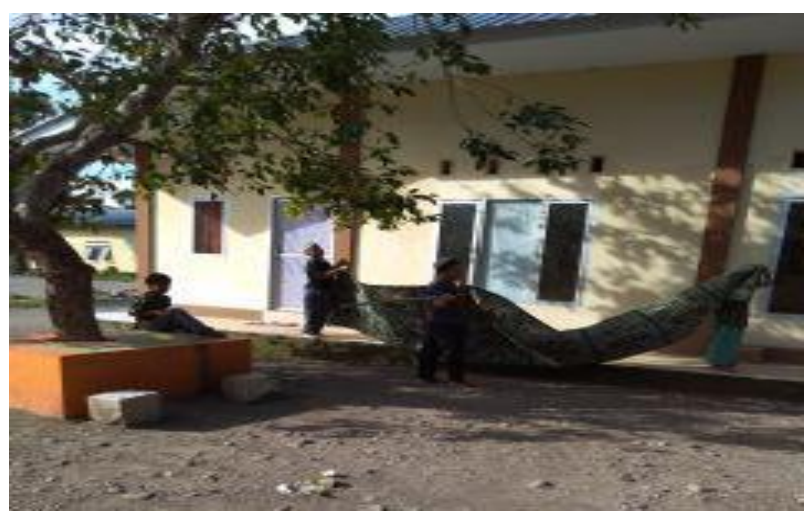

\section{Gambar 5. Kerja Bakti Membersihkan Lingkungan Ponpes}

Selain dari program kerja di atas, mahasiswa KKN STIBA Makassar juga mengadakan buka puasa bersama, setiap Senin dan Kamis. Kegiatan ini bertujuan untuk membiasakan para santri menghidupkan sunnah nabi melalui puasa Senin dan Kamis.

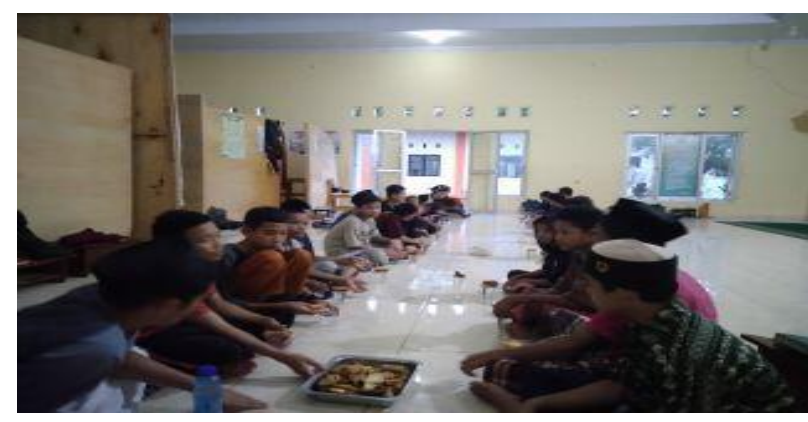

\section{Gambar 6. Buka Puasa Bersama Senin dan Kamis}

Hasil kegiatan dari seluruh program kerja yang dilaksanakan di atas memberikan perubahan yang cukup positif untuk para santri. Dari yang awalnya mereka hanya fokus pada pembelajaran formal dan hafalan Al-Qur'an saja, setelah itu mereka jauh lebih terlatih untuk berceramah di depan umum, sekaligus bisa menjadi imam salat di tengah masyarakat. Keberlangsungan setiap program 
yang telah dilaksanakan diharapkan dapat ditindaklanjuti lebih serius oleh pihak pesantren. Demi memberikan pembinaan yang terbaik untuk para santri.

\section{KESIMPULAN}

Pelaksanaan kuliah kerja nyata (KKN) ini merupakan suatu langkah awal yang baik bagi mahasiswa STIBA Makassar untuk ikut serta berkontribusi dalam lingkup masyarakat luas, khususnya di bidang keagamaan. Adapun dukungan dari pihak pemerintah, tokoh masyarakat dan pembina pesantren, memberi harapan besar agar ke depannya alumni dari STIBA Makassar sudah siap mengabdi di tengah masyarakat, memberikan manfaat yang jauh lebih luas. Pada pelaksanaan KKN di Pondok Pesantren Ulul Albab, dapat disimpulkan bahwa manajemen pembinaan butuh untuk ditingkatkan. Untuk itu, mengingat banyaknya perubahan lingkungan di era modern saat ini, menuntut para santri untuk bisa menyesuaikan kemampuan dan kualitas diri sebelum terjun di tengah masyarakat.

\section{DAFTAR PUSTAKA}

Ariesman, Ariesman. "Sketsa Dakwah dan Pembinaan Qur'ani Masyarakat Desa Mangeloreng Melalui KKN STIBA Makassar." WAHATUL MUJTAMA': Jurnal Pengabdian Masyarakat 1.1 (2020): 13-32.

Azizah, Nurul, Jamilatur Rohmah, Miftahul Mushlih, and Paramitha Amelia Kusumawardani. "Phbs Santri Dan Aplikasi Poskestren Pondok Pesantren Al-Hamdaniyah Buduran Siwalan Panji Sidaorjo." Jurnal Pengabdian Masyarakat Dalam Kesehatan 2, no. 1 (2020): 22. https://doi.org/10.20473/jpmk.v2i1.19583.

Ibrahim, Rustam. "Pesantren Dan Pengabdian Masyarakat (Studi Kasus Pondok Pesantren Dawar Boyolali)." Al-Tahrir: Jurnal Pemikiran Islam 16, no. 1 (2016): 89. https://doi.org/10.21154/al-tahrir.v16i1.316.

Patuti, Asnawati. "Pelaksanaan Program Pendekatan Keagamaan melalui KKN STIBA Makassar di Desa Baruga Kabupaten Maros." WAHATUL MUJTAMA': Jurnal Pengabdian Masyarakat 1.2 (2020): 185-199.

Tempo, Rachmat Bin Badani, and Khaerul Aqbar. "Ikhtiar Mahasiswa KKN STIBA Makassar dalam Pembentukan Akhlak Qur'ani Masyarakat Desa Balassuka Kabupaten Gowa." WAHATUL MUJTAMA': Jurnal Pengabdian Masyarakat 1.1 (2020): 90-115. 